\title{
Exposure Assessment Based Recommendations to Improve Nanosafety at Nanoliposome Production Sites
}

\author{
Christophe Bressot, ${ }^{1}$ Neeraj Shandilya, ${ }^{1,2}$ Eugénia Sofia da Costa Nogueira,, \\ Artur Cavaco-Paulo, ${ }^{4}$ Martin Morgeneyer, ${ }^{2}$ Olivier Le Bihan, ${ }^{1}$ and Olivier Aguerre-Chariol ${ }^{1}$ \\ ${ }^{1}$ Institut National de l'Environnement Industriel et des Risques (INERIS), Verneuil en Halatte, France \\ ${ }^{2}$ Génie des Procédés Industriels, Sorbonne Universités, Université de Technologie de Compiègne (UTC), Compiègne, France \\ ${ }^{3}$ Centre of Molecular and Environmental Biology (CBMA), Department of Biology, University of Minho, Campus of Gualtar, \\ Braga, Portugal \\ ${ }^{4}$ Centre of Biological Engineering (CEB), University of Minho, Campus of Gualtar, Braga, Portugal
}

Correspondence should be addressed to Christophe Bressot; christophe.bressot@ineris.fr

Received 1 July 2015; Revised 14 September 2015; Accepted 20 September 2015

Academic Editor: Enrico Bergamaschi

Copyright (C) 2015 Christophe Bressot et al. This is an open access article distributed under the Creative Commons Attribution License, which permits unrestricted use, distribution, and reproduction in any medium, provided the original work is properly cited.

\begin{abstract}
The NANOFOL concept aims at creating nanodevices containing a drug for inflammatory disorder treatment. This paper provides recommendations for nanosafety based on a measurement campaign which aimed at identifying exposure risks with respect to two specific phases of the product's lifecycle, that is, production of the device and its waste management. The nanoparticle's presence both in air and in liquid phase was studied. While no emissions were detected during the production period, many recommendations have been made, particularly regarding the nanowaste treatment, based on nanosafety guidelines.
\end{abstract}

\section{Introduction}

NANOFOL [1] was a European Project supported through the Seventh Framework Programme for Research and Technological Development. It aims at improving the treatment of chronic inflammatory diseases by the development and production of nanobiodevices (i.e., nanoliposomes) in nanosafe conditions. Nanoliposomes are nanosized vesicles made mainly of phospholipids, able to enclose molecules, and used as device to facilitate drug transport and penetration into cells. As a result, a part of this project is devoted to nanosafety management with different operations which are used to deal with nanorisk during production and waste management. Nanosafety is a function of two distinct factors, exposure (of workers) and hazard (toxicity/ecotoxicity of nanomaterial). One of the most widely applied standards for exposure assessment at workplaces is EN 689, 1995 [2]. This standard enlists the critical points that need to be addressed for a fair evaluation of these two factors. Table 1 summarizes these points. In addition, the standard also enlists two preventive measures to deal for the safety of workers.
As far as the handling and manipulation of the nanosuspensions are concerned, there is no such standard available as per the knowledge of the authors. Moreover, the two abovementioned factors exposure and hazards are still rather poorly understood in the context of nanosuspensions [3]. Nanosuspensions are biphasic systems consisting of pure drug particles (or nanostructured vesicles like liposomes) dispersed in an aqueous solvent, stabilized by surfactants. With the ability to improve the stability as well as the bioavailability of poorly soluble drugs and easiness to prepare, these nanosuspensions are becoming a vital technology in the pharmaceutical sector [4]. Hence, it is critical to control the exposure and hazards associated during their manipulation for their sustainable development. This has been a subject of interest of some European Community regulations, for example, the EC directives 1998 [5] and EP and EC directives 2004 [6]. The main application of these nanosuspensions is in the production of nanomedicines. The nanostructured compounds used in nanomedicine are rarely reported as a main risk [7-9]. Nanomedicine is a relatively new topic in the 
TABLE 1: Factors to be considered in exposure assessment as enlisted by NF EN 689, 1995.

\begin{tabular}{ll}
\hline Description & Points to be addressed \\
& $\begin{array}{l}\text { (a) Number of sources emitting pollution } \\
\text { (b) Size of the production in relation to production } \\
\text { capacity } \\
\text { (c) Size of each of the sources }\end{array}$ \\
& (d) Type and location of each source \\
\hline Probability & (a) Dispersion of pollutants by air movement \\
of exposure & $\begin{array}{l}\text { (b) Proximity to sources/confinement barrier } \\
\text { (c) Time spent in a location }\end{array}$ \\
\hline Preventive & (a) Type and efficacy of evacuation and ventilation \\
measures & $\begin{array}{l}\text { systems } \\
\text { (b) Personal working habits }\end{array}$ \\
\hline
\end{tabular}

nanorisk framework and the amount of chemical compounds involved seems to be low compared with industrial products containing nanomaterials [10].

Elsaesser and Howard [11] reported the need to develop a regulatory framework based on objective scientific research which will limit human exposure to safe levels of the unwanted engineered nanomaterials in the environment. This approach requires a different framework which balances the therapeutic benefit against the potential risk to worker and the environment. In spite of clear improvements of risk assessment to drive nanodevice conception to safer drug delivery [12-18], to our knowledge no studies concerning nanomedicine safety at the workplace have been published.

However nanomedicine recommendations in healthcare sector [19] or general guideline on nanosafety [20-23] can also be applied in the context of nanomedicine production workplace. In case of nanosuspension manipulation, converging recommendations consist consequently to handle liquid dispersions with adapted personal protective equipment (e.g., nitrile gloves, lab coats, and safety glasses) under a fume hood. The complementary works that have studied the nanosuspensions report that the hazards related to nanosuspension are not only influenced by the particle nature but also by the dispersant, for example, [24]. Here, the main recommendation focuses on the manipulated quantities more than one litre and the nature of the used dispersant (i.e., flammable, toxic, etc.). In case of nanoparticle production under high pressure conditions, a significant risk of nanoparticle aerosolization has been identified. Lee et al. [25] and Johnson et al. [26] reported aerosolization during energetic process using carbon nanotube suspensions. It is the understanding of the authors that such a behavior of carbon nanotube suspensions can also be expected in case of nanoliposome suspensions. Daigle et al. [27] asserted that the likely exposure route to engineered nanomaterials is through inhalation, though ingestion or dermal penetration may also occur [28-30].

The exposure measurement in presence of nanomaterial use implicates an evaluation of data gathering to estimate the nanorisk or the critical periods which necessitate a measurement campaign. These measurements are intended, whether a nanorisk is identified, to provide evidence for the nanoparticle presence within the breathing zone of the workers during the period of nanomaterial use. An appropriate method to perform an exposure measurement campaign consists of an assessment campaign with a particle counter and sizer and, if necessary, a complementary campaign of measurements [31-34].

The present paper assesses the potential of this method in an industry-like laboratory that produces nanoliposome liquid suspensions. It aims at assessing the exposure to nanoparticles and at providing recommendations with respect to this. The three steps of this assessment have been

(i) to identify and quantify the sources of nanostructured particle emissions in the production facility,

(ii) to characterize the emitted aerosol particles in terms of number concentration,

(iii) to manage the nanoliposome waste in the production facility by cracking the inherent nanostructure of the membrane,

(iv) to propose recommendations by means of concrete measures for the alleviation of the potential exposure in case of an accident.

A particle counter is used to quantify the number concentration of the aerosol particles with an aerosol sampler to characterize their shape and elemental composition. The latter also allows for identifying the probable nanoliposome emissions with certainty as a particle counter cannot differentiate between the process and background related aerosol particles.

\section{Materials and Methods}

2.1. Measurement Strategy. Various attempts have been made in the past to develop a comprehensive assessment strategy for the measurement campaigns at workplaces or production sites [34-36]. The design of the assessment strategy relies on the choice of the exposure measurement instruments which in turn depends upon the purpose of the measurement (as outlined by [37, 38]). Besides this, the extensitivity, longevity, and background aerosols ladening (originating from the work environment or the process itself) of the assessment procedure and the production site's structure or architecture also play key roles while designing the strategy. In the present work, the investigated production site is the laboratory of University of Minho (UMINHO) on the Campus of Azurém of Guimarães (Portugal) which produces the liquid suspension of the nanoliposomes for manufacturing nanodrugs which are used for various inflammatory disorder treatments. As shown in Figure 1, the laboratory is divided in two parts. The first part is used to store samples and chemical compounds in a fridge and the second area is used to handle compounds and produce nanoliposomes. All sorts of product handling or processing are performed inside the conformity of a fume hood or directly on the laboratory benches (marked as $\mathrm{A}, \mathrm{B}$, and $\mathrm{C}$ ). To reduce operators' risks of exposure, the two key means of action are the air flow and protective equipment. 


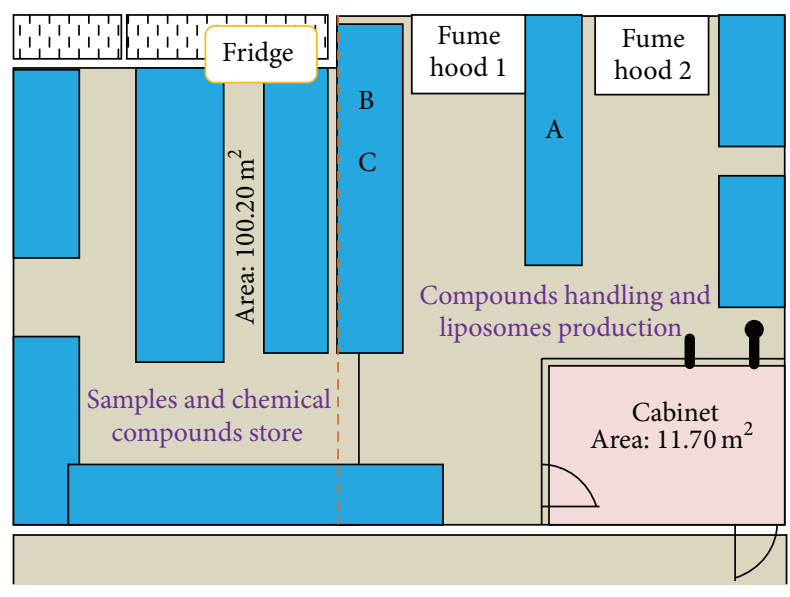

FIGURE 1: Nanoliposome liquid suspension producing laboratory floor plan.

The ventilation controls were kept switched off during the measurement campaign and the air flow was consequently natural in the laboratory. The protective equipment used for the operator's protection is nitrile gloves, safety goggles, cotton lab coat, and mask.

The different steps during the production process are presented in Figure 2. The first step consists in weighing various chemical compounds as dioleoylphosphatidylethanolamine (DOPE), cholesterol $(\mathrm{CH})$, or ( $\mathrm{N}$-(carbonylmethoxypolyethylene glycol-2000)-1,2-distearoyl-sn-glycero-3phosphoethanolamine) DSPE-MPEG using a digital balance and placing them under the fume hood. In the second step of handling, these chemical compounds are mixed with chloroform in definite ratios inside the fume hood 1.

The chloroform is then evaporated inside fume hood 2 during the third step. During fourth step, a lipid film is prepared on a round bottom flask to prepare for the nanoliposomes production. This is performed mainly on the laboratory bench A; see Figure 1. Until this step, no nanostructured product is present and consequently there is no risk of exposure to nanoliposomes. The dried lipid film is treated with phosphate buffered saline (PBS) to prepare its suspension which is followed by the suspension's vortex mixing, to yield multilamellar vesicles (MLVs) the first step when the nanoliposomes are manufactured. Consequently, this could be the first moment when their emission might occur. The extrusion step, through polycarbonate filters, uses a pressure system, to form large unilamellar vesicles. Following extrusion, these nanoliposomes are purified or separated from the residue by passing the mixture through a SPE column. Like extrusion, this step could also be a potential source of nanoliposomes emission and could drive to an inhalation or dermal exposure risk. Both of these steps are carried out at $\mathrm{A}$ and $\mathrm{C}$ places (Figure 1). The DOPE-containing liposomes formulation is used to stabilize the bilayer form through the addition of a cleavable lipid derivative of polyethylene glycol (DSPE-MPEG). This new nanobiodevice has been developed by UMINHO and tested by other partners and seems to be the best candidate to be used [3]. Approximately a duration

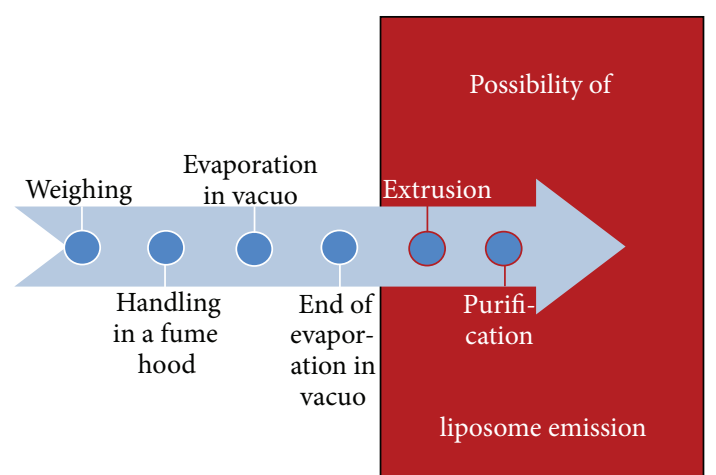

FIGURE 2: A series of steps involved during the production process of nanoliposome liquid suspensions; the last two steps, that is, extrusion and purification of these suspensions, are considered to be the steps during which possible emissions of nanoliposomes might occur.

of 1 hour 30 minutes is required to produce liquid suspension of $15 \mathrm{~mL}$ containing nanoliposomes with a liposomal formulation DOPE/CH/DSPE-MPEG concentration of $11.9 \mathrm{mM}$ at the purification step. The production batch can be repeated 5 times in a day and necessitates only one worker.

Hence, we consider these two stages, that is, extrusion and purification to be sole potential periods of emission. As a result, the particle counting and sampling should be done within this zone only.

Further to the risk of emission to the air, the liquid suspensions represent an inherent possible accidental source of nanoparticles.

2.2. Nanoliposome Liquid Suspension Analysis. Before starting the measurement campaign, a characterization of the final product, that is, nanoliposome liquid suspension, was carried out. In Figure 3, scattering intensity-weighted particle size distribution of the nanoliposome liquid suspension, manufactured by producer, is shown. It was carried out using Zetasizer Nano ZS (Malvern Instruments) by means of Dynamic Light Scattering (DLS). A monodispersed distribution of the nanoliposomes, with a mode just below $100 \mathrm{~nm}$, can be observed.

For the Transmission Electron Microcopy (TEM, Model CM12; Philips, Netherlands; shown in Figure 4), $8 \mu \mathrm{L}$ droplet from this suspension was deposited on a TEM copper mesh grid (Model S162; Formvar/Carbon, Quantifoil Micro Tools $\mathrm{GmbH}$, Germany). The mesh grid was made hydrophilic by its plasma treatment, $0.1 \mathrm{mbar}, 45 \mathrm{~mA}$, and $3 \mathrm{~min}$ (Model K100X, Glow Discharge, Emitech, Quorum Technologies Ltd., UK), prior to drop deposition. After the deposition, the grid was then allowed to dry in a closed chamber so that the aqueous content gets evaporated and the nanoliposomes rest deposited on the grid. Since many nanoliposomes get destroyed during drying, a lot of disrupted membranes are observed in TEM microscopy (examples marked by solid black arrows in Figure 4). Fortunately, the nanoliposomes provided by UMINHO are so stable that some of them are still observable after drying (examples marked by dashed 


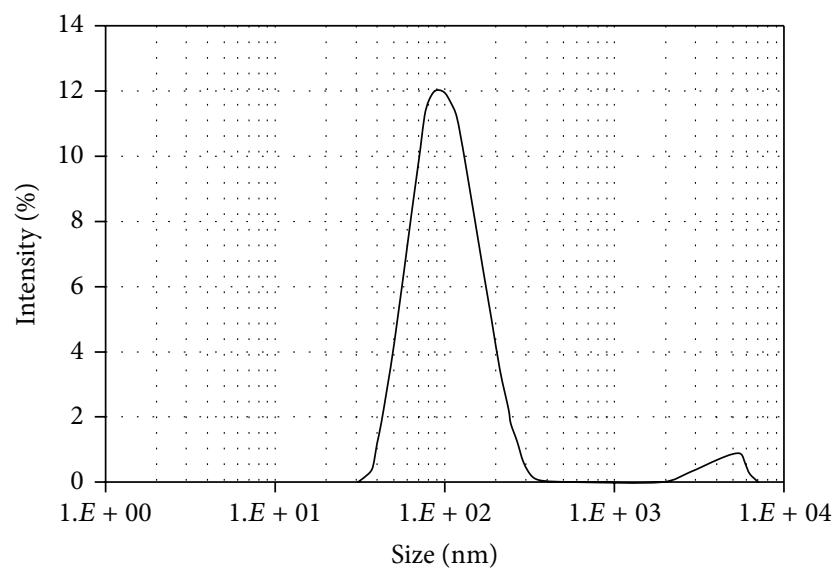

Figure 3: Particle size distribution of the liposome liquid suspension obtained using DLS.

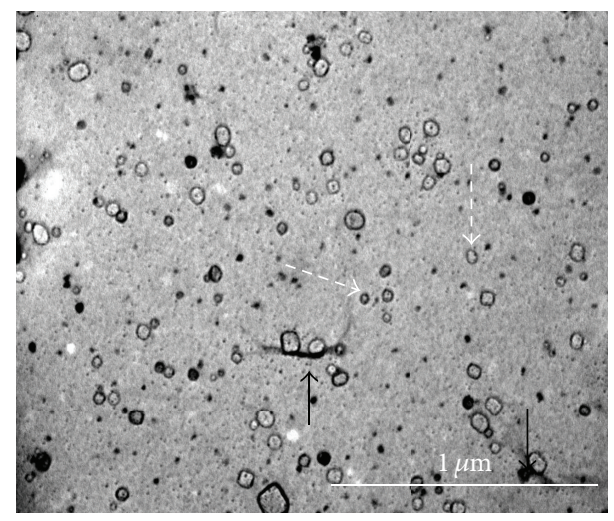

FIgURE 4: TEM image of the liposomes obtained after drying a deposited drop of its liquid suspension on a grid; examples of liposomes with disrupted membranes are marked with black arrows and those with stable membrane are marked with white arrows.

white arrows in Figure 4). The size of the nanoliposomes, in Figure 4 , is in a size range of $75 \mathrm{~nm}$ to $\sim 1 \mu \mathrm{m}$ with small vesicles in the range of 75 to $150 \mathrm{~nm}$. These observations are consistent with the previous observations of DLS sizing (Figure 3). The Energy Dispersive X-ray (EDS) analysis of the droplet revealed the chemical elements present in the membrane. An example is shown in Figure 5. Most of the elements found are ubiquitous like $\mathrm{Cl}, \mathrm{C}, \mathrm{Na}, \mathrm{Al}, \mathrm{Si}$, and $\mathrm{K}$. To be certain of the nature of the sampled aerosol particles during exposure analysis, the need of a tracer element is indispensable since this distinguishes the nanoliposomes from the background particles. For this, the tracer element (i) should be present inside the vesicular membrane, (ii) should not to be present in the laboratory environment, and (iii) should be easily identifiable. The only element satisfying these criteria is phosphorus $(\mathrm{P})$ which is present in the phospholipid membranes. Another criterion that can be taken into account in order to further confirm the release of aerosolized nanoliposome is its spherical shape as most of the background particles are irregularly shaped.

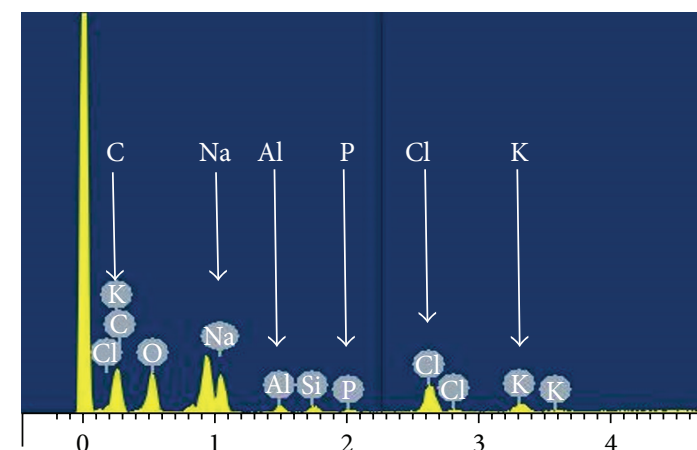

FIGURE 5: Elemental composition of one nanoliposome with $\mathrm{C}, \mathrm{Na}$, $\mathrm{Cl}, \mathrm{K}, \mathrm{Al}$, and $\mathrm{P}$.

2.3. Exposure Analysis. The choice of the exposure measurement device was guided by two factors: (i) portability and easiness to manage; (ii) ability to measure nanosized particles. Considering these two factors, the exposure analysis during the production of the nanoliposomes was carried out using a Condensation Particle Counter (CPC 3007, TSI Inc.) which measures particles in the size range from $10 \mathrm{~nm}$ to $1 \mu \mathrm{m}$. The sampling time was kept at $1 \mathrm{~s}$ with an air flow rate equal to $0.7 \mathrm{~L} / \mathrm{min}$. The CPC 3007 was complemented with a Mini Particle Sampler (MPS; Ecomesure) [39]. It is used for aerosol particles collection through filtration technique on porous copper mesh grids (Model S143-3; Quantifoil Micro Tools GmbH Germany). The use of a sampler is imperative here because a particle counter is generally insensitive to particle source or composition and makes it difficult to differentiate between background and process-related aerosol particles. Once collected, these particles then can be analyzed through TEM in order to confirm their nature, that is, background particles or nanoliposomes.

\section{Exposure Assessment Results}

The exposure assessment with respect to the production phase of the product was carried out in three steps:

(a) Preliminary or "naked eye" evaluation of the exposure on the basis of the points enlisted in Table 1 .

(b) Measurement and analysis of the background aerosol particles with no production activity.

(c) Measurement and analysis of the aerosol particles during production activity.

Following this investigation, the waste management phase needed to be considered; see Section 4 .

3.1. Data Evaluation Based on EN 689. The points enlisted in Table 1 were analyzed for the present production site and observations were made corresponding to each point. Table 2 summarizes the results.

In Table 2, two main exposure sources are mentioned: nanoliposomes production and their waste disposal. This part of the campaign has provided a visual perception of the workplace (process and work practices) to define the 
TABLE 2: Responses to the factors considered (field study) [2].

\begin{tabular}{|c|c|c|}
\hline Description & Points to be addressed & Observations on the production site \\
\hline \multirow{4}{*}{ Hazard } & $\begin{array}{l}\text { (a) Number of sources emitting } \\
\text { pollution }\end{array}$ & Three sources: extruder, storage, and garbage \\
\hline & $\begin{array}{l}\text { (b) Size of the production and waste } \\
\text { generation in relation to the } \\
\text { production capacity }\end{array}$ & $\begin{array}{l}\text { A daily intensive production ( } 5 \text { batches per day) produces } 75 \mathrm{~mL} \text {. If we } \\
\text { consider } 260 \text { days/year of production, the maximum total production is } \\
19,500 \mathrm{~mL} / \text { year. The phospholipid concentration in } \\
\text { dioleoylphosphatidylethanolamine (DOPE) is } 6.43 \mathrm{mM}(4.78 \mathrm{mg} / \mathrm{mL}) \text { in the } \\
\text { final product } \\
\text { The waste consists of residues from water based solution which is used to } \\
\text { clean the extruder and tools }\end{array}$ \\
\hline & (c) Size of each of the sources & $\begin{array}{l}\text { During extrusion and storage phases, } 15 \mathrm{~mL} \text { of nanoliposome suspension is } \\
\text { dealt with }\end{array}$ \\
\hline & (d) Type and location of each source & $\begin{array}{l}\text { (a) Nanoliposomes production on the three benches A, B, and C, } \\
\text { (b) fridge, (c) garbage (Figure 1) }\end{array}$ \\
\hline \multirow{3}{*}{$\begin{array}{l}\text { Probability of } \\
\text { exposure }\end{array}$} & $\begin{array}{l}\text { (a) Dispersion of pollutants by air } \\
\text { movement }\end{array}$ & There was neither any measured dispersion nor any ATEX risk identified \\
\hline & $\begin{array}{l}\text { (b) Proximity to sources/confinement } \\
\text { barrier }\end{array}$ & Handling without hood \\
\hline & (c) Time passed in a location & $\begin{array}{l}10 \mathrm{~min} \text { for handling the nanoliposome liquid suspensions, } 60 \mathrm{~min} \text { for their } \\
\text { extrusion, and } 30 \mathrm{~min} \text { for their purification }\end{array}$ \\
\hline \multirow{2}{*}{$\begin{array}{l}\text { Preventive } \\
\text { measures }\end{array}$} & $\begin{array}{l}\text { (a) Type and efficacy of evacuation and } \\
\text { ventilation systems }\end{array}$ & $\begin{array}{l}\text { Presence of hood for chemical and biological products; no measured } \\
\text { dispersion }\end{array}$ \\
\hline & (b) Personal working habits & $\begin{array}{l}\text { In accordance with the chemical/biological risk } \\
\text { No direct account taken yet of nanorisk }\end{array}$ \\
\hline
\end{tabular}

TABLE 3: Statistic data and the observations from the TEM analysis obtained during the three measurement steps.

\begin{tabular}{lccccc}
\hline & $\begin{array}{c}\text { Mean conc. } \\
\left(\# / \mathrm{cm}^{3}\right)\end{array}$ & $\begin{array}{c}\text { Min } \\
\left(\# / \mathrm{cm}^{3}\right)\end{array}$ & $\begin{array}{c}\text { Max } \\
\left(\# / \mathrm{cm}^{3}\right)\end{array}$ & $\begin{array}{c}\text { Std. Dev. } \\
\left(\# / \mathrm{cm}^{3}\right)\end{array}$ & TEM analysis \\
\hline Background & 16764 & 13469 & 29818 & 2188 & Oil droplets, soot building debris \\
Extrusion & 11250 & 9189 & 27388 & 822 & Oil droplets or soot; no nanoliposomes detected \\
Purification & 38583 & 21440 & 72180 & 7375 & Oil droplets, soot building debris; no nanoliposomes detected \\
\hline
\end{tabular}

sampling points which could be the potential sources of emission during production. At the same time, the information collected during this part has also provided useful inputs, like details regarding ventilation and personal protection equipment, to carry out the risk assessment studies. Since there is high nanoliposome stability after drying, therefore, an easy and efficient management of their safe disposal is equally crucial.

3.2. Measurement Results. In Figure 6, the aerosol particles concentration, obtained using CPC 3007, is shown for the background particles as well as for the particles emitted during extrusion and purification steps of the nanoliposomes production. As already mentioned in Table 2, the duration of the extrusion and purification steps are $60 \mathrm{~min}$ and $30 \mathrm{~min}$, respectively. For the background particles, the mean concentration $\approx 17,000 \# / \mathrm{cm}^{3}$ with a standard deviation $\approx 2,200 \# / \mathrm{cm}^{3}$ which proves relatively high fluctuations in the laboratory air (see Table 3). Towards the end, an increase in the concentration can be observed $\left(\approx 30,000 \# / \mathrm{cm}^{3}\right)$. Such fluctuations are very frequent to be observed at any production site, especially when the source of ventilation is natural, as in the present case.
The TEM analysis of the background particles, sampled at $t=10: 46$, reveals the typical nature of any particle usually found in ambient air, that is, droplets of oil, soot (Figure 7(a)), and rare cement-type materials (Figure 7(b)). The overview shows a moderately loaded grid with a common duration sampling of 6 minutes where drops of oil seem to be predominant.

Coming back to Figure 6, with respect to the background particle, no significant change in the number concentration can be observed during extrusion. The TEM images of the aerosol particles, sampled during this step, are shown in Figures $8(\mathrm{a})$ and $8(\mathrm{~b})$. Like number concentration, there is no change in their nature too. Same type of oil droplets (Figure 8(a)) or soot (Figure $8(\mathrm{~b})$ ) was observed during extrusion phase.

In contrast with the extrusion, the purification step does give rise to an increase in the number concentration (mean concentration $\approx 39,000 \# / \mathrm{cm}^{3}$ ) (Figure 6). This is the highest mean value obtained during the campaign with maximum concentration reaching $72,000 \# / \mathrm{cm}^{3}$. Different peaks in the number concentration curve can be attributed to the opening/closing of the doors in the weighing room which perturbs the air flow of the laboratory. The absence of nanoliposomes 


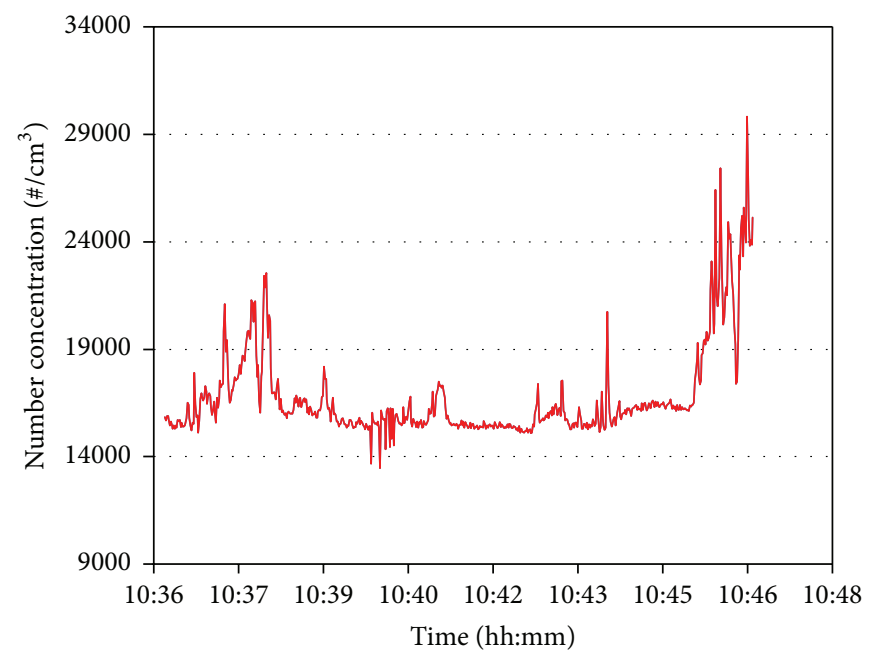

(a)

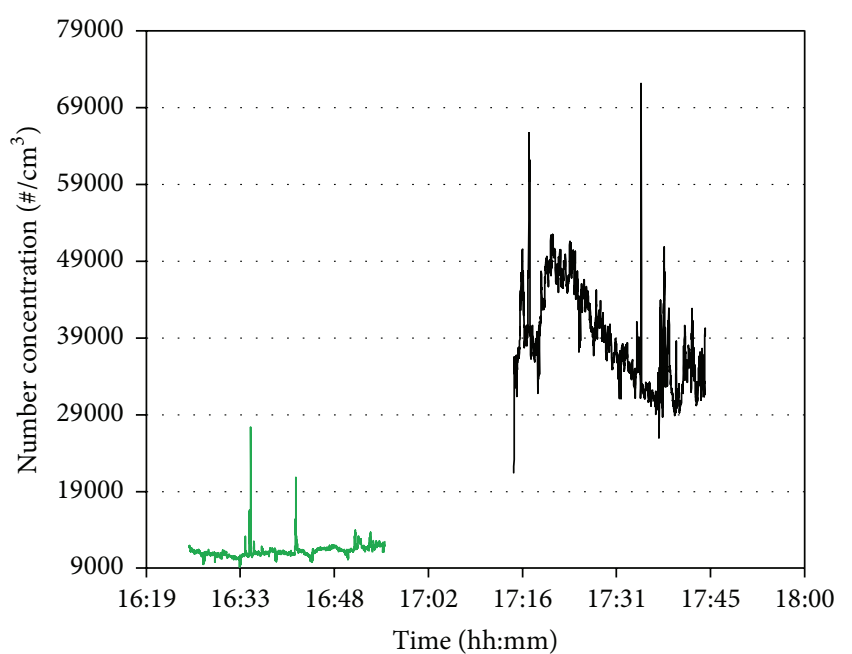

(b)

FIGURE 6: (a) Number concentration of the background particles and (b) the ambient airborne particles in the vicinity of the fume hood 1 (breathing zone of the worker) during the extrusion (green color) and purification (black color) of the nanoliposome liquid suspensions.

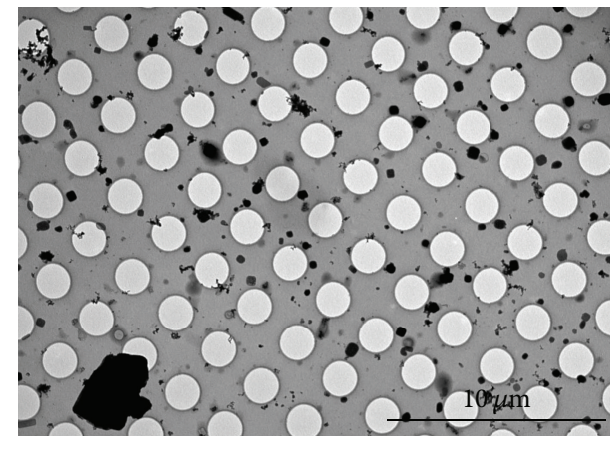

(a)

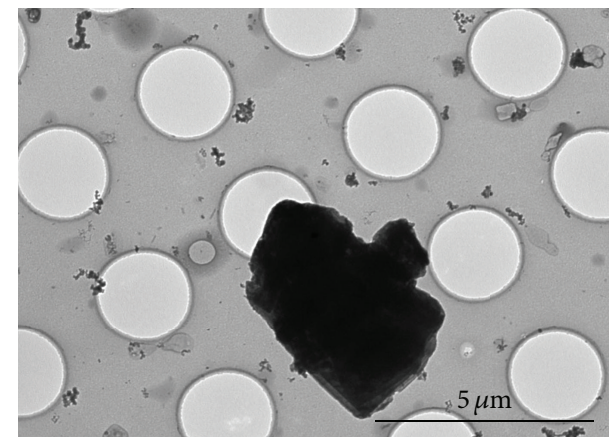

(b)

FIGURE 7: (a) Overview of the sampled particles from the background; (b) typical cement-type debris present in the ambient air.

emission during purification is confirmed from the TEM images of the sampled aerosol particles (Figures 9(a) and 9(b)) which like earlier TEM images also contain soot and oil droplets.

Hence, in all the activities during production process, the phosphorus element is never detected in the particles tested on the grids. Therefore, despite the intensive research and data collection during both particle counting and aerosols sampling in the laboratory, it has not been possible to identify nanoliposomes observed in Figure 4. All the peaks in the number concentration of the aerosol particles, during either extrusion or purification, are associated with perturbations in the laboratory's air flow due to the incidents like the turning on/off of the fume hood, doors opening/close, and so forth.

\section{Nanowaste Management}

Nanowaste management has been emphasized recently due to free or agglomerated nanoparticle release characterization in smoke or incineration residue $[40,41]$. In case of nanoparticles present in sewage due, for example, to feces/urine, one part of this pollution is detected in the treated effluent [4244].

In the framework of this study, the experimentally simulated waste treatment consisted of a dilution by PBS followed by thermal cracking to manage the nanorisk posed by the waste. To test the destruction of DOPE formulations of nanoliposome, we diluted the $20 \mu \mathrm{L}$ sample of the suspension provided by UMINHO into $10 \mathrm{~mL}$ of PBS $(1 / 50 \mathrm{v} / \mathrm{v})$ at ambient temperature, followed by heating at $60^{\circ} \mathrm{C}$ for 10 hours. Consequently, there was a complete destruction of the suspension sample. To illustrate this, Figures 10(a), 10(b), and 10(c) show a shift of the size mode from $100 \mathrm{~nm}$ (Figure 10(a)) to around $1000 \mathrm{~nm}$ (Figure 10(c)) which shows a complete destruction of the nanostructure of the nanoliposome.

\section{Recommendations for Nanosafety}

No significant emission-compared to the background noise-was observed during the whole campaign. However, the possibility of exposure of humans to the emitted nanostructured material cannot be excluded in case of an 


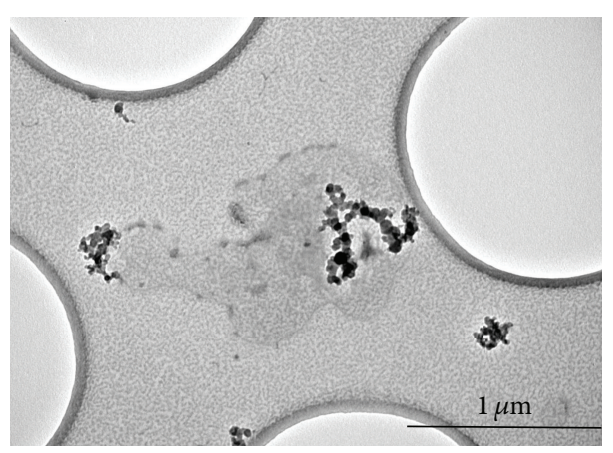

(a)

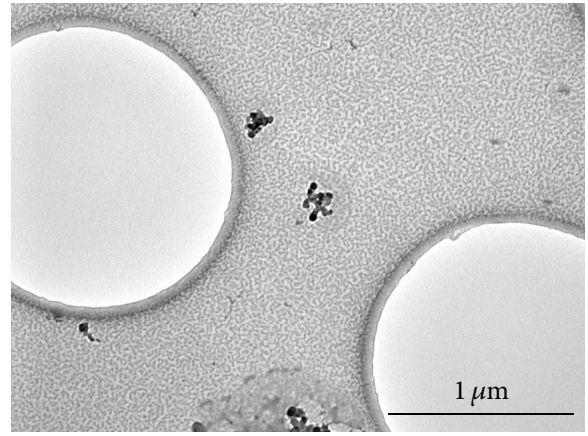

(b)

FIGURE 8: Typical TEM image examples of (a) soot and oil droplets (main compound carbon and iron) and (b) soot (main compound carbon) reaped during the airborne particles collection while the worker filters the liquid suspensions.

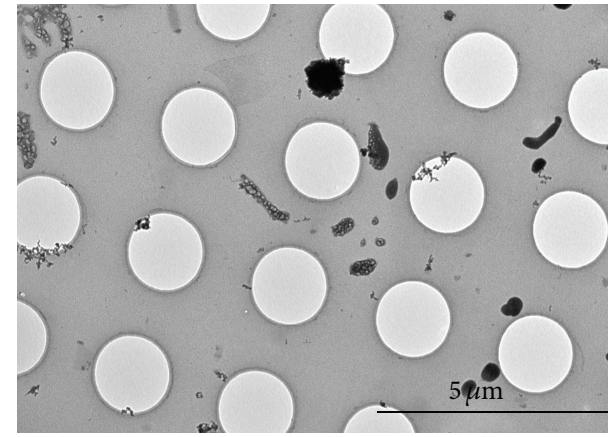

(a)

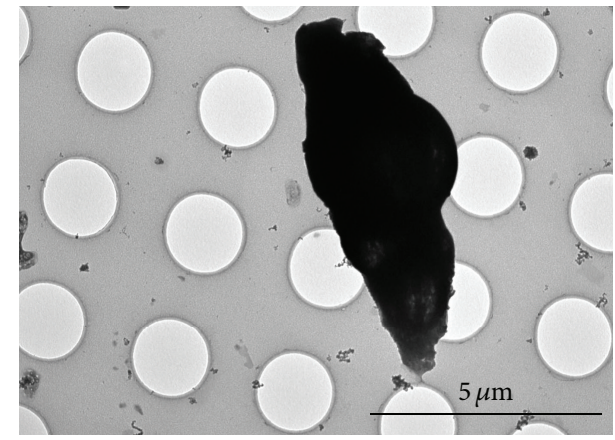

(b)

FIGURE 9: (a) Typical overview of TEM grid with oil droplets and soot; (b) presence of big cement-type material on the TEM grid during the purification step.

accident, even though the workers involved in the production of nanoliposomes at UMINHO are protected by the use of nitrile gloves, cotton lab coat, and sometimes safety glasses. Considering this, the following recommendations are made here for future producers of devices in order to improve nanosecurity:

(a) All the operations of production of nanoliposomes should be carried out in each step under a closed conformity of a fume hood, particularly the extrusion and the purification of nanoliposomes activities.

(b) Two nitrile gloves per hand should be worn during all handling operations.

(c) During transport, a double containment of all materials should be implemented. Plastic bags with air tight zips can be used to wrap, for example.

(d) All the storages of nanomaterials should be clearly labeled.

(e) A proposition for a dilution-cracking based procedure for destroying the nanostructure of the nanoliposomes, thus simplifying the nanowaste management, has been made in the present study. The producers should use such a method to enhance the nanosafety with respect to their nanowaste.

\section{Conclusion}

During the campaign at the production site of the nanoliposome suspensions, an attentive study of the whole manufacturing process was carried out. Using the NF EN 689 standard, initial evaluations of possible sources of nanoliposome emissions were made. The quantification of the aerosol particles in the vicinity or within the breathing zone of these sources did not show any significant increase in their number concentration during various production activities. Their sampling showed the only presence of oil droplets or soot which are common particles of the urban aerosols produced by the human activity (traffic, heating). However, considering the nanowaste management and unanticipated accidents at the production site, simple and effective method and guidelines have also been proposed to ensure nanosafety.

\section{Conflict of Interests}

The authors declare that there is no conflict of interests regarding the publication of this paper.

\section{Acknowledgments}

Eugénia Nogueira (SFRH/BD/81269/2011) holds scholarships from Fundação para a Ciência e a Tecnologia (FCT). The 


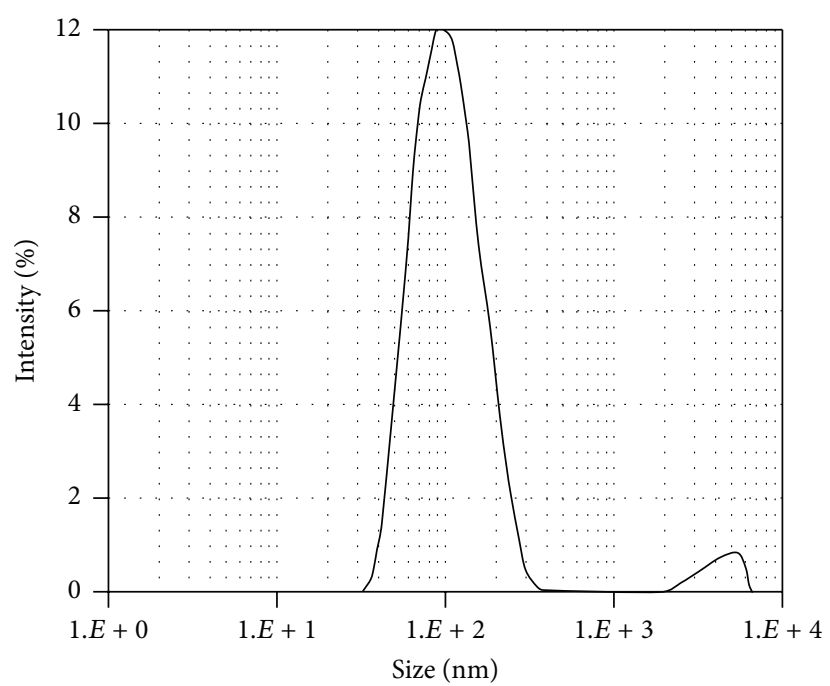

(a)

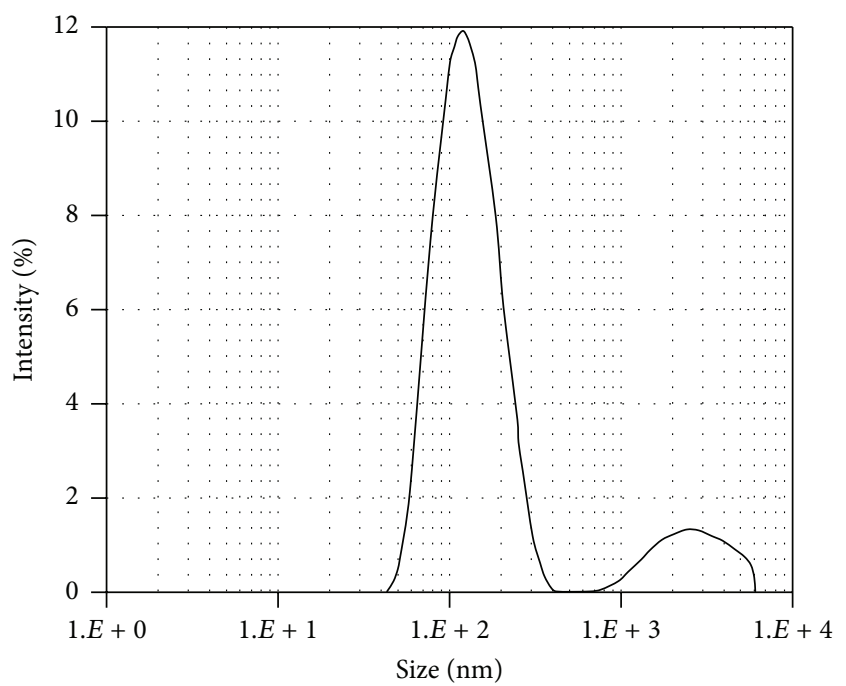

(b)

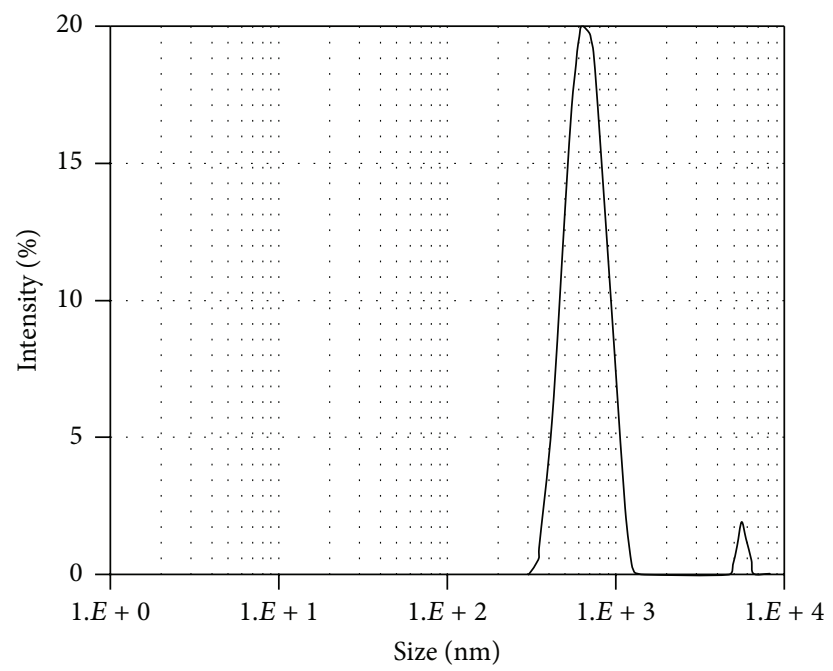

(c)

FIgURE 10: (a) The initial particle size distribution of the diluted nanoliposome liquid suspension provided by UMINHO ( $20 \mu \mathrm{L}$ of nanoliposome suspension in $10 \mathrm{~mL}$ of PBS) placed in contact with hydrogen peroxide $(30 \% \mathrm{v} / \mathrm{v})$ at the same proportion $(1 / 1 \mathrm{v} / \mathrm{v})$, (b) after 4 hours, and (c) after 10 hours.

authors thank the EC for funding from the European Union Seventh Framework Programme (FP7/2007-2013) under Grant Agreement NMP4-LA-2009-228827 NANOFOL.

\section{References}

[1] http://www.nanofol.eu/.

[2] NF EN 689, "Atmosphères des lieux de travail-Conseils pour l'évaluation de l'exposition aux agents chimiques aux fins de comparaison avec des valeurs limites et stratégie de mesurage," Juillet 1995.

[3] E. Nogueira, A. Loureiro, P. Nogueira et al., "Liposome and protein based stealth nanoparticles," Faraday Discussions, vol. 166, pp. 417-429, 2013.

[4] N. Arunkumar, M. Deecaraman, and C. Rani, "Nanosuspension technology and its applications in drug delivery," Asian Journal of Pharmaceutics, vol. 3, no. 3, pp. 168-173, 2009.
[5] European Council, "European Council of EU Directive 98/24/EC of 7 April 1998 on the protection of the health and safety of workers from the risks related to chemical agents at work," Official Journal of the European Union, vol. 131, pp. 11-23, 1998.

[6] EP and Council of EU, "Directive 2004/37/EC of 29 April 2004 on the protection of workers from the risks related to exposure to carcinogens or mutagens at work," Official Journal of the European Union, vol. 158, pp. 50-76, 2004.

[7] K. L. Aillon, Y. Xie, N. El-Gendy, C. J. Berkland, and M. L. Forrest, "Effects of nanomaterial physicochemical properties on in vivo toxicity," Advanced Drug Delivery Reviews, vol. 61, no. 6, pp. 457-466, 2009.

[8] R. Duncan and R. Gaspar, "Nanomedicine(s) under the microscope," Molecular Pharmaceutics, vol. 8, no. 6, pp. 2101-2141, 2011. 
[9] S. Parveen, R. Misra, and S. K. Sahoo, "Nanoparticles: a boon to drug delivery, therapeutics, diagnostics and imaging," Nanomedicine: Nanotechnology, Biology, and Medicine, vol. 8, no. 2, pp. 147-166, 2012.

[10] C. Bekker, D. H. Brouwer, E. Tielemans, and A. Pronk, "Industrial production and professional application of manufactured nanomaterials-enabled end products in dutch industries: potential for exposure," Annals of Occupational Hygiene, vol. 57, no. 3, pp. 314-327, 2013.

[11] A. Elsaesser and C. V. Howard, "Toxicology of nanoparticles," Advanced Drug Delivery Reviews, vol. 64, no. 2, pp. 129-137, 2012.

[12] T. O. McDonald, M. Siccardi, D. Moss et al., "The application of nanotechnology to drug delivery in medicine," in Nanoengineering, P. I. Dolez, Ed., chapter 2.2, pp. 173-223, Elsevier, Amsterdam, The Netherlands, 2015.

[13] L. Juillerat-Jeanneret, M. Dusinska, L. M. Fjellsbo et al., "Biological impact assessment of nanomaterial used in nanomedicine. Introduction to the NanoTEST project," Nanotoxicology, vol. 9, supplement 1, pp. 5-12, 2015.

[14] R. Guadagnini, B. H. Kenzaoui, L. Walker et al., "Toxicity screenings of nanomaterials: challenges due to interference with assay processes and components of classic in vitro tests," Nanotoxicology, vol. 9, supplement 1, pp. 13-24, 2015.

[15] M. Dusinska, S. Boland, M. Saunders et al., "Towards an alternative testing strategy for nanomaterials used in nanomedicine: lessons from NanoTEST,' Nanotoxicology, vol. 9, supplement 1, pp. 118-132, 2015.

[16] G. Oberdörster, "Safety assessment for nanotechnology and nanomedicine: concepts of nanotoxicology," Journal of Internal Medicine, vol. 267, no. 1, pp. 89-105, 2010.

[17] A. M. Nyström and B. Fadeel, "Safety assessment of nanomaterials: implications for nanomedicine," Journal of Controlled Release, vol. 161, no. 2, pp. 403-408, 2012.

[18] W. Wohlleben, T. A. J. Kuhlbusch, J. Schnekenburger, and C. M. Lehr, Eds., Safety of Nanomaterials along Their Lifecycle: Release, Exposure, and Human Hazards, CRC Press, 2014.

[19] European Agency for Safety and Health at Work (EUOSHA), E-Fact 73: Nanomaterials in the Healthcare Sector: Occupational Risks and Prevention, vol. 14, European Agency for Safety and Health at Work (EU-OSHA), 2013, https:/osha.europa.eu/en/tools-and-publications/publications/ e-facts/e-fact-73-nanomaterials-in-the-healthcare-sectoroccupational-risks-and-prevention/view.

[20] U. Vogel, D. Brouwer, M. Berges, M. van Tongeren, K. Savolainen, and Q. Wu, Handbook of Nanosafety: Measurement, Exposure and Toxicology, Academic Press, Burlington, Mass, USA, 2013.

[21] M. Mirabile, F. Boccuni, D. Gagliardi, B. M. Rondinone, and S. Iavicoli, "Workplace exposure to engineered nanomaterials: the Italian path for the definition of occupational health and safety policies," Health Policy, vol. 117, no. 1, pp. 128-134, 2014.

[22] European Comission, Guidance on the Protection of the Health and Safety of Workers from the Potential Risks Related to Nanomaterials at Work. Guidance for Employers and Health and Safety Practitioners, European Comission, 2013.

[23] European Agency for Safety and Health at Work (EU-OSHA), "E-fact 72: Tools for the management of nanomaterials in the workplace and prevention measures,18," 2013, https://osha.europa.eu/en/tools-and-publications/publications/ e-facts/e-fact-72-tools-for-the-management-of-nanomaterialsin-the-workplace-and-prevention-measures/view.
[24] A. Groso and T. Meyer, "Concerns related to Safety Management of Engineered Nanomaterials in research environment," Journal of Physics: Conference Series, vol. 429, no. 1, Article ID 012065, 2013.

[25] J. H. Lee, S.-B. Lee, G. N. Bae et al., "Exposure assessment of carbon nanotube manufacturing workplaces," Inhalation Toxicology, vol. 22, no. 5, pp. 369-381, 2010.

[26] D. R. Johnson, M. M. Methner, A. J. Kennedy, and J. A. Steevens, "Potential for occupational exposure to engineered carbonbased nanomaterials in environmental laboratory studies," Environmental Health Perspectives, vol. 118, no. 1, pp. 49-54, 2010.

[27] C. C. Daigle, D. C. Chalupa, F. R. Gibb et al., "Ultrafine particle deposition in humans during rest and exercise," Inhalation Toxicology, vol. 15, no. 6, pp. 539-552, 2003.

[28] S. S. Tinkle, J. M. Antonini, B. A. Rich et al., "Skin as a route of exposure and sensitization in chronic beryllium disease," Environmental Health Perspectives, vol. 111, no. 9, pp. 1202-1208, 2003.

[29] R. Aitken, K. Creely, and C. Tran, "Nanoparticles: an occupational hygiene review," HSE Research Report 274, UK Health \& Safety Executive (HSE), Bootle, UK, 2004.

[30] J. S. Brown, K. L. Zeman, and W. D. Bennett, "Ultrafine particle deposition and clearance in the healthy and obstructed lung," American Journal of Respiratory and Critical Care Medicine, vol. 166, no. 9, pp. 1240-1247, 2002.

[31] M. Klenke, "First results for safe procedures for handling nanoparticles," Dissemination Report, Nanosafe, 2008, http://www.nanosafe.org/home/liblocal/docs/Dissemination\%20report/DR6_s.pdf.

[32] F. Tardif, Y. Sicard, A. Shakesheff, C. Moehlmann, and U. Backmann, "Is it possible to easily measure the engineered, nanoparticles at workplaces?" Dissemination Report, Nanosafe, 2008, http://www.nanosafe.org/home/liblocal/docs/ Dissemination report/DR3_s.pdf.

[33] O. Witschger, O. Le Bihan, M. Reynier et al., "INRS-CEAINERIS guide: Préconisations en matière de caractérisation des potentiels d'émission et d'exposition professionnelle aux aérosols lors d'opérations mettant en œuvre des nanomatériaux," ND 2355, ND 2355-226-12, INRS, http:// www.ineris.fr/centredoc/guide-méthodologique-cea-inerisinrs-v14-1386772834.pdf.

[34] O. Witchger, O. Le Bihan, M. Reynier, C. Durand, and D. Charpentier, "Préconisation en matière de caratérisation et d'exposition des potentiels d'émission et d'exposition professionnelle aux aérosols lors d'opérations nanomatériaux," INRS, Hygiène et Sécurité au Travail, vol. 226, pp. 41-55, 2012.

[35] D. Brouwer, B. van Duuren-Stuurman, M. Berges, E. Jankowska, D. Bard, and D. Mark, "From workplace air measurement results toward estimates of exposure? Development of a strategy to assess exposure to manufactured nano-objects," Journal of Nanoparticle Research, vol. 11, no. 8, pp. 1867-1881, 2009.

[36] M. Methner, L. Hodson, and C. Geraci, "Nanoparticle emission assessment technique (NEAT) for the identification and measurement of potential inhalation exposure to engineered nanomaterials part a," Journal of Occupational and Environmental Hygiene, vol. 7, no. 3, pp. 127-132, 2010.

[37] H. Kaminski, M. Beyer, H. Fissan, C. Asbach, and T. A. J. Kuhlbusch, "Measurements of nanoscale $\mathrm{TiO}_{2}$ and $\mathrm{Al}_{2} \mathrm{O}_{3}$ in industrial workplace environments-methodology and results," Aerosol and Air Quality Research, vol. 15, pp. 129-141, 2015. 
[38] T. A. J. Kuhlbusch, C. Asbach, H. Fissan, D. Göhler, and M. Stintz, "Nanoparticle exposure at nanotechnology workplaces: a review," Particle and Fibre Toxicology, vol. 8, article 22, 2011.

[39] B. R'Mili, O. L. C. Le Bihan, C. Dutouquet, O. Aguerre-Charriol, and E. Frejafon, "Particle sampling by TEM grid filtration," Aerosol Science and Technology, vol. 47, no. 7, pp. 767-775, 2013.

[40] T. Walser, L. K. Limbach, R. Brogioli et al., "Persistence of engineered nanoparticles in a municipal solid-waste incineration plant," Nature Nanotechnology, vol. 7, no. 8, pp. 520-524, 2012.

[41] G. Ounoughene, O. Le Bihan, C. Chivas-Joly et al., "Behavior and Fate of Halloysite Nanotubes (HNTs) when incinerating PA6/HNTs nanocomposite," Environmental Science \& Technology, vol. 49, no. 9, pp. 5450-5457, 2015.

[42] A. Weir, P. Westerhoff, L. Fabricius, K. Hristovski, and N. Von Goetz, "Titanium dioxide nanoparticles in food and personal care products," Environmental Science and Technology, vol. 46, no. 4, pp. 2242-2250, 2012.

[43] M. A. Kiser, P. Westerhoff, T. Benn, Y. Wang, J. Pérez-Rivera, and K. Hristovski, "Titanium nanomaterial removal and release from wastewater treatment plants," Environmental Science and Technology, vol. 43, no. 17, pp. 6757-6763, 2009.

[44] P. Westerhoff, G. X. Song, K. Hristovski, and M. A. Kiser, "Occurrence and removal of titanium at full scale wastewater treatment plants: implications for $\mathrm{TiO}_{2}$ nanomaterials," Journal of Environmental Monitoring, vol. 13, no. 5, pp. 1195-1203, 2011. 

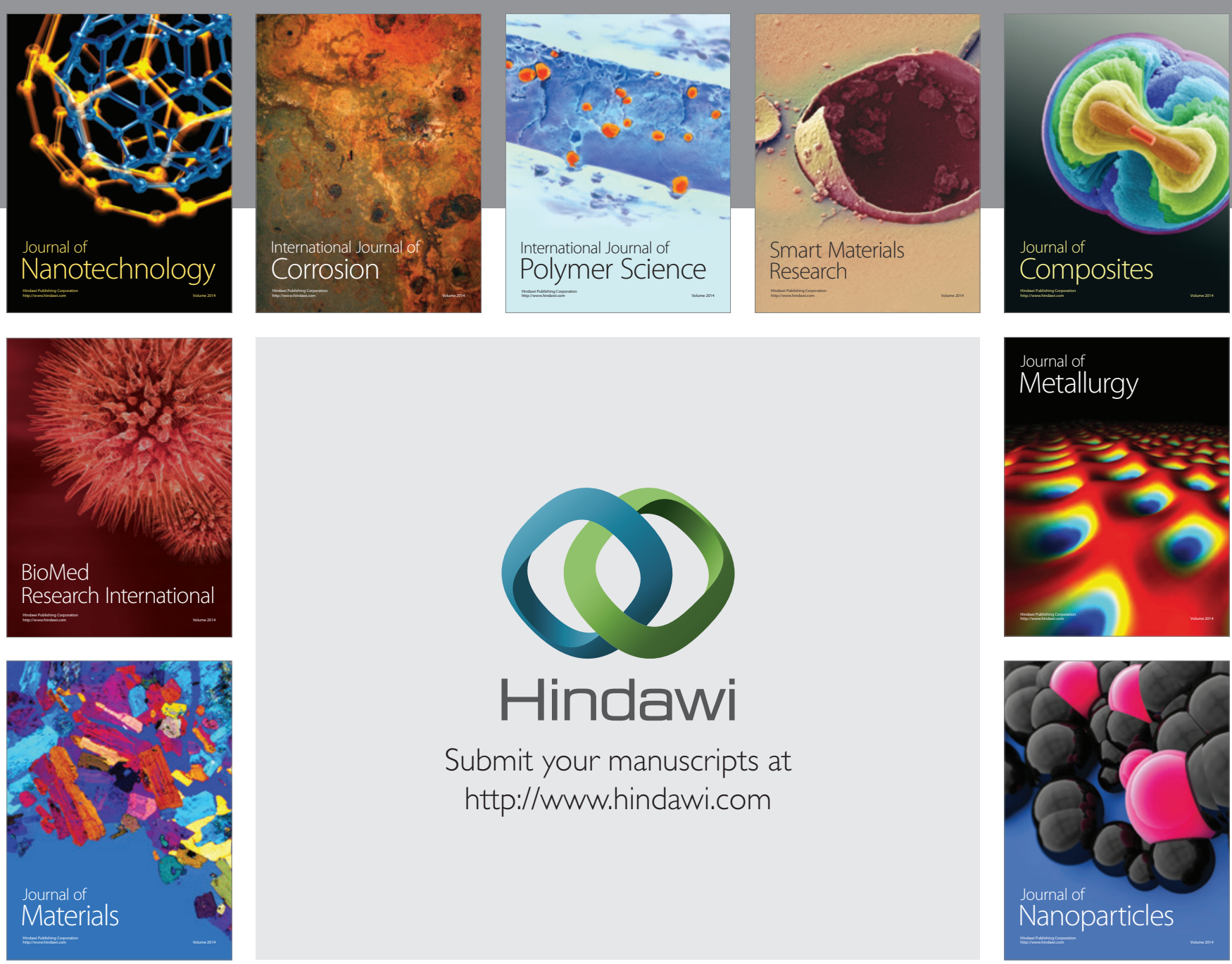

Submit your manuscripts at http://www.hindawi.com
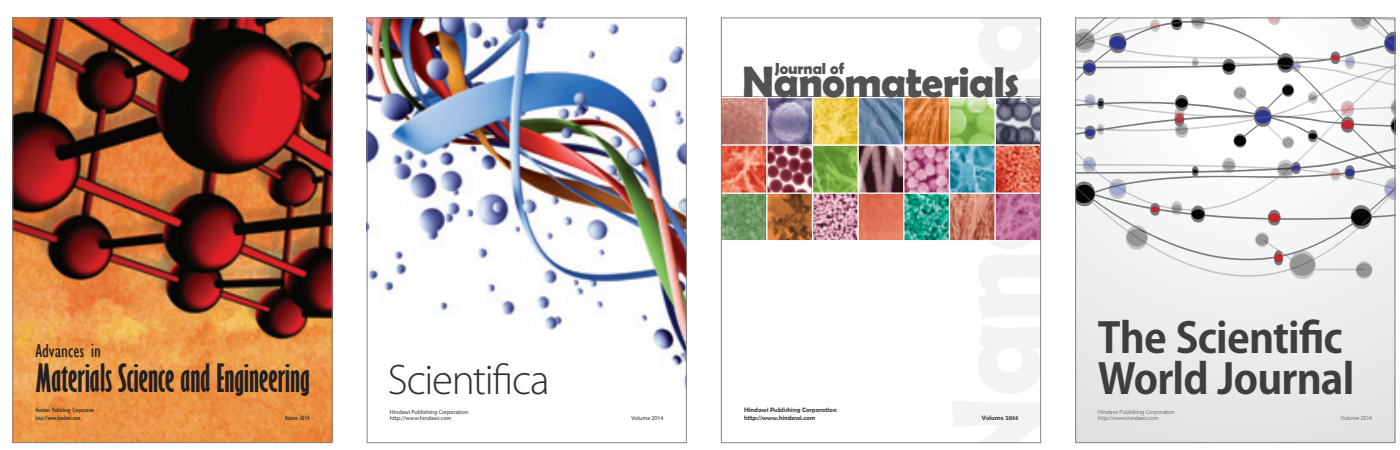

\section{The Scientific World Journal}
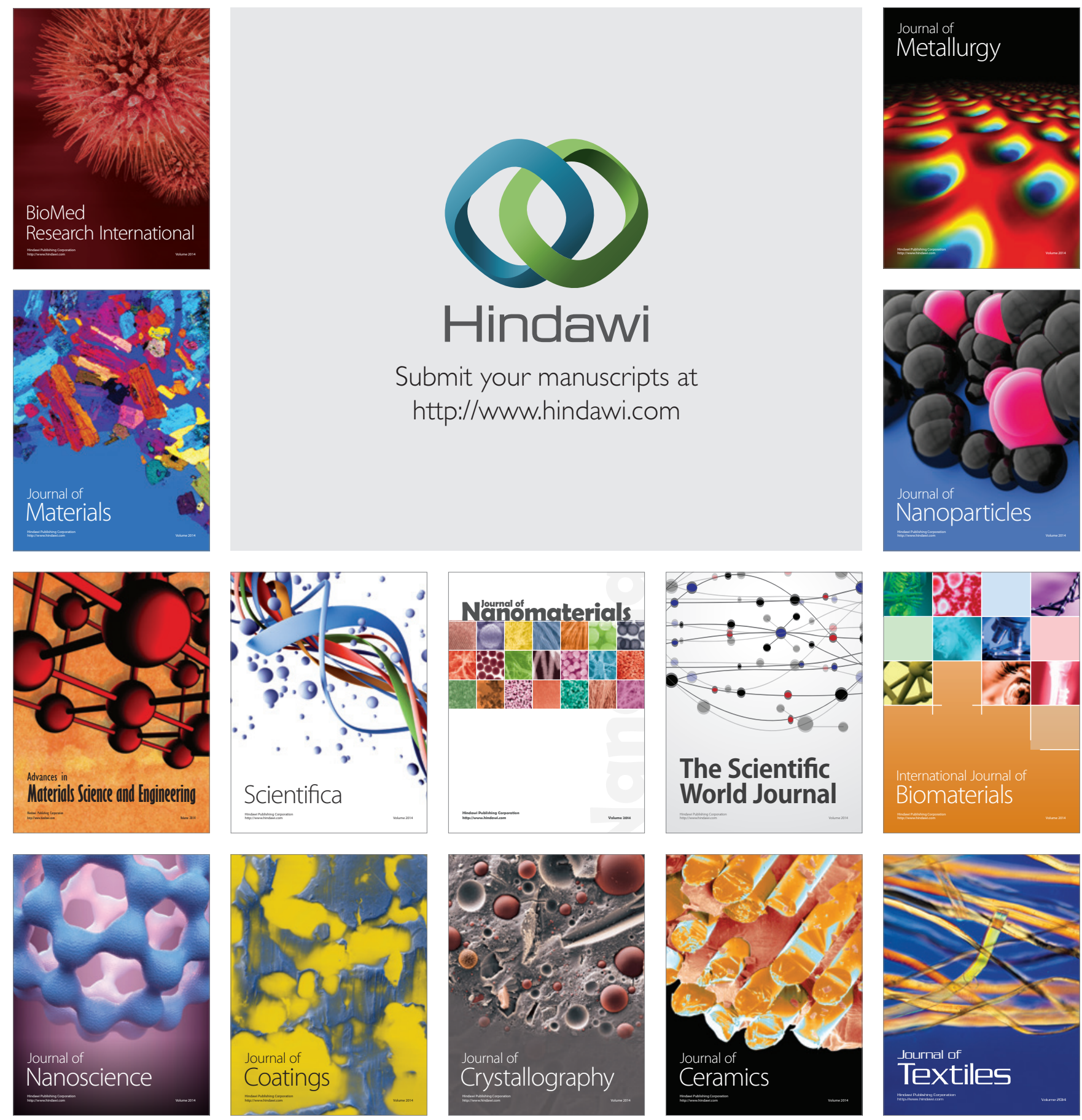